\title{
Instrumentos de apoio às exportações e taxas múltiplas de câmbio no Brasil *
}

\author{
Marco Flávio da Cunha Resende ${ }^{* *}$ \\ Gustavo Britto ${ }^{* * *}$ \\ Frederico G. Jayme Jr. \\ Mauro Borges Lemos ${ }^{* * * * *}$
}

\begin{abstract}
Resumo
O objetivo deste artigo é apresentar uma metodologia de cálculo do impacto das políticas de promoção das exportações sobre as taxas de câmbio reais setoriais no Brasil. Há, no País, instrumentos de promoção das exportações que ensejam ganhos fiscais e financeiros aos exportadores. Tais instrumentos podem ser compreendidos como mecanismos de alteração da taxa de câmbio real com a qual o exportador opera efetivamente. Para medir essa alteração, são calculadas taxas de câmbio por setor CNAE (Classificação Nacional de Atividades Economicas) a dois dígitos para o período em que há dados disponíveis, ou seja, 2004-2008. Os resultados obtidos mostram que os ganhos potenciais são heterogêneos quando se consideram os diferentes setores da economia e os diferentes mecanismos de apoio às exportações brasileiras. Este trabalho contribui para a literatura através do cálculo de indicadores inéditos, além de abrir o debate acerca de instrumentos modernos de apoio ao setor exportador da economia brasileira.
\end{abstract}

Palavras-chave: Políticas de incentivo das exportações; Câmbio real setorial; Brasil.

\section{Abstract \\ Exports promoting policies and multiples exchange rates in Brazil}

This paper presents a methodology to estimate the impact of selected export promoting policies on the real exchange rate in Brazil. Currently, there are a number of policy instruments that generate fiscal and financial benefits to Brazilian exporters. These instruments can be viewed as mechanisms to alter the real exchange rate with which exporters effectively operate. To measure this change, real exchange rates are calculated for two-digit sector CNAE (Economic Activities National Classification) codes from 2004 to 2008. The results show that potential gains are heterogeneous across distinct policy instruments for exports promotion as well as across sectors. The article contributes to the specific literature, by calculating unprecedented indicators and opening a debate on the importance of modern policy tools to foster exports in Brazil.

Keywords: Exports policies; Real exchange rate; Brazil.

JEL E60, F13, H20.

${ }^{*}$ Trabalho recebido em 14 de dezembro de 2011 e aprovado em 18 de janeiro de 2013. Os autores agradecem o apoio do CNPq (Conselho Nacional de Desenvolvimento Científico e Tecnológico).

** Professor Adjunto do Departamento de Ciências Econômicas do Centro de Desenvolvimento e Planejamento Regional (Cedeplar) da Universidade Federal de Minas Gerais (UFMG), Belo Horizonte, MG, Brasil. E-mail: resende@cedeplar.ufmg.br.

*** Professor Adjunto do Departamento de Ciências Econômicas do Cedeplar /UFMG. E-mail: gustavo@ cedeplar.ufmg.br.

**** Professor Associado do Departamento de Ciências Econômicas do Cedeplar / UFMG. E-mail: gonzaga@cedeplar.ufmg.br.

***** Professor Titular do Departamento de Ciências Econômicas do Cedeplar / UFMG. E-mail: mbl@ cedeplar.ufmg.br.

Economia e Sociedade, Campinas, v. 23, n. 1 (50), p. 107-129, abr. 2014. 


\section{Introdução}

O desempenho da balança comercial brasileira na primeira década dos anos 2000 como também seu papel no arrefecimento da restrição externa sobre o crescimento do produto interno bruto representaram um divisor de águas em relação à história econômica recente do Brasil. De fato, após duas décadas de grande instabilidade econômica durante as quais a trajetória de crescimento das exportações apresentou um comportamento anticíclico, o que se observou, nos últimos anos, foi um crescimento consistente das exportações e do PIB.

Entre 2000 e 2010, o valor das exportações nacionais cresceu a uma taxa média de $15 \%{ }^{1}$. A partir de 2006 , com a aceleração do crescimento do mercado interno e a apreciação da taxa de câmbio real, o saldo da conta corrente se deteriorou, tornando-se negativo a partir de 2008 em virtude, em boa medida, da queda acentuada do superávit comercial nesse período. Mesmo nesse quadro, a manutenção de taxas elevadas de crescimento do valor exportado criou uma margem suficiente para a acomodação do crescimento das importações, garantindo um superávit comercial que oscilou entre US\$ 24,8 bilhões e US\$ 20,2 bilhões nos anos 2008 e 2010.

Esses eventos trazem de volta os elementos centrais do debate acerca das características estruturais e das reais possibilidades de desenvolvimento de países periféricos realizado no âmbito da Cepal (Bielschowsky, 2000; Rodríguez, 2009). Em particular, surge a possibilidade de renovação, em novas bases, do debate acerca da permanente tendência ao desequilíbrio externo da industrialização periférica, presente nos escritos originais de Prebisch (1949) e desenvolvida, paulatinamente, durante os anos 1950 e 1960, e dos instrumentos de política fundamentais para a garantia do desenvolvimento da América Latina.

Com a exaustão do modelo de desenvolvimento baseado na industrialização substitutiva, o debate acerca dos instrumentos de política passou a se mover, a partir dos anos 1980 (em reação às experiências de sucesso de países asiáticos), com crescente força, nos anos 1990 (devido às reformas liberalizantes), da necessidade de controle das importações para os benefícios do crescimento das exportações. Assim, o que se observa no Brasil é um movimento lento, mas progressivo, de substituição, não planejada, dos instrumentos de política que deram suporte à industrialização substitutiva por diversos mecanismos de apoio ao setor exportador. Esses instrumentos, juntamente com os demais elementos determinantes do crescimento das exportações, possuem uma função importante na explicação do recente sucesso exportador observado no Brasil e, primordialmente, estabelece uma oportunidade para se pensar novos mecanismos e novas políticas que possam potencializar os resultados recentes.

(1) Entre 2000 e 2008, a taxa foi superior a $17 \%$. 
Essas questões são tão mais evidentes quando se consideram os efeitos da recente crise da economia mundial. Para países como o Brasil, a instabilidade da economia internacional gera impactos importantes sobre o saldo comercial. Isso ocorre seja devido ao menor crescimento da renda mundial, seja devido à maior restrição ao crédito externo requerido para o financiamento das exportações, ou, ainda, em função da oscilação dos preços das commodities no mercado internacional e do recrudescimento de políticas protecionistas por parte dos parceiros comerciais.

A mudança no cenário econômico mundial e doméstico reforça o papel central das exportações para o desempenho da economia brasileira, uma vez que o comércio exterior estimula o crescimento da economia e o equilíbrio no seu setor externo. De acordo com a literatura especializada, além das características competitivas ligadas às elasticidades-renda da demanda, os principais determinantes das exportações de um país são sua taxa de câmbio real, a renda doméstica e a renda mundial (Cavalcanti; Ribeiro, 1998).

No que se refere à taxa de câmbio real como um dos determinantes das exportações, os mecanismos de promoção das exportações podem ser vistos como formas de alteração da taxa de câmbio real com a qual o exportador opera efetivamente. Essa alteração ocorre quando se considera que as políticas de estímulo às exportações podem proporcionar ganhos fiscais e financeiros aos exportadores. Tais ganhos variam entre empresas e entre os setores da atividade econômica. Tomando-se a média desses ganhos para as empresas exportadoras de um mesmo setor, teríamos, então, variações dos ganhos fiscais e financeiros entre setores com efeitos distintos sobre as taxas de câmbio reais setoriais. Ou seja, o câmbio melhorado pelas políticas de promoção das exportações aumenta implicitamente o preço de exportação em cada setor da atividade produtiva brasileira. Desse modo, é possível interpretar os ganhos fiscais e financeiros obtidos nos vários setores exportadores da economia como diferenças nas taxas de câmbio setoriais.

Assim, na prática, enquanto se verificavam taxas de câmbio diferenciadas para a importação e para a exportação no Brasil nos anos 1950 e 1960 (Tavares, 1979; Dib, 1985; Lessa, 1983), os mecanismos modernos de estímulo às exportações acabaram por recriar "taxas múltiplas de câmbio" para os exportadores. Argumentase que, nos anos 2000, os mecanismos e políticas de apoio às exportações cumpriram o papel de arrefecer as assimetrias competitivas relacionadas à reprodução dinâmica da heterogeneidade estrutural. Ou seja, autores da Cepal, tais como Pinto (2000), defenderam a tese da heterogeneidade estrutural no âmbito da relação centro $\mathrm{x}$ periferia. Segundo essa tese, os níveis de produtividade, de incorporação do progresso técnico e de renda per capita seriam radicalmente diferentes entre centro e periferia. Desse modo, a heterogeneidade estrutural tornar-se-ia responsável por uma inserção pouco competitiva da periferia no comércio internacional, 
principalmente no que diz respeito à competitividade não preço dos bens e serviços comercializáveis. A resultante desse quadro seria não só uma dinâmica específica da balança comercial do país periférico como também da conta capital e financeira de seu balanço de pagamentos. Portanto, políticas de promoção das exportações, embora não solucionem o problema das assimetrias competitivas, podem mitigar os efeitos deletérios sobre o setor externo da economia periférica que decorrem da reprodução dinâmica da heterogeneidade estrutural, visto que tais políticas ensejam ganhos fiscais e financeiros para os exportadores.

No caso do Brasil, as principais fontes de ganhos fiscais e financeiros vinculados à atividade de exportação são as operações de Adiantamento de Contrato de Câmbio (ACC) e Pagamento Antecipado das Exportações (PAE), operações observadas no âmbito do regime de Drawback, operações relativas ao Proex e, ainda, às linhas de financiamento às exportações do BNDES (Exim).

O objetivo deste trabalho é apresentar uma metodologia de cálculo do impacto das políticas de promoção das exportações sobre os setores exportadores no Brasil. Para isso, são calculadas múltiplas taxas de câmbio setoriais. Utilizam-se dados inéditos dos mecanismos de promoção das exportações concedidos por diversas instituições públicas brasileiras, como o Banco Central do Brasil (Bacen), o Banco Nacional de Desenvolvimento Econômico e Social (BNDES) e o Banco do Brasil (BB). O exercício foi realizado para o período no qual os dados estão disponíveis com o nível de agregação necessário, ou seja, 2004-2008². Assim, espera-se que o trabalho contribua para a literatura por meio do cálculo desses indicadores inéditos, além de abrir o debate acerca de instrumentos modernos de apoio ao setor produtivo de economias periféricas.

Este artigo conta com três seções, além desta introdução. Na primeira seção, é apresentada a metodologia do cômputo das taxas de câmbio reais setoriais, que incorpora os ganhos fiscais e financeiros associados à atividade de exportação no Brasil. A segunda seção registra os resultados empíricos das taxas de câmbio setoriais para o período 2004-2008 a partir da metodologia discutida na seção anterior. A última seção expõe as conclusões do trabalho.

\section{Taxa de câmbio implícita}

A taxa de câmbio real é um indicador do preço relativo dos bens comerciáveis vis$\grave{a}$-vis os bens não comerciáveis no conjunto da economia e se relaciona diretamente

(2) Pereira e Maciente (2000) calcularam o aumento da rentabilidade das exportações agregadas brasileiras decorrente dos ganhos financeiros presentes nas operações dos exportadores com Adiantamento de Contratos e Câmbio (ACC) e Adiantamento de Contratos de Exportação (ACE) para o período 1993-1998. Neste trabalho, serão calculadas as taxas de câmbio setoriais associadas não somente às operações de ACC, mas também às operações de PAE, PROEX, financiamentos do BNDES e Drawback para o período 2004-2008. As operações de ACE foram extintas antes do período em análise neste trabalho. 
com o custo de oportunidade da firma em exportar. A firma deve decidir sobre o mix de produção destinado ao mercado doméstico e ao mercado externo, dado seu estoque de capital. Assumindo-se custos de produção iguais, seja quando a firma exporta ou quando sua produção é destinada ao mercado doméstico, sua receita é obtida pelo valor de Q.E.P. ${ }_{f}^{*}$, quando a produção é exportada, e por $Q . P_{f}$, quando é vendida no mercado interno, sendo $Q=$ quantidade produzida pela firma; $P_{f}^{*}=$ preço no mercado internacional do produto exportado pela firma; $P_{f}=$ preço no mercado doméstico do produto produzido pela firma; $E=$ taxa de câmbio nominal.

Assim, o custo de oportunidade de exportar da firma refere-se ao ganho que a mesma teria em usar seu estoque de capital para produzir para o mercado interno $^{3}$. Esse custo de oportunidade pode ser calculado por setor de atividade econômica (setor CNAE), segundo o cômputo da taxa de câmbio real setorial, dado por $\frac{\left(E . P_{i}{ }^{*}\right)}{P}$, onde $E=$ taxa de câmbio nominal; $P_{i}{ }^{*}=$ nível de preços do setor $\underline{i}$ (setor CNAE) ${ }^{P}$ no mercado internacional; $P_{i}=$ nível de preços do setor i (setor CNAE) no mercado doméstico. Portanto, a taxa de câmbio real setorial reflete a receita de exportações que o produtor teria ao exportar sua produção em relação à receita que ele teria se destinasse sua produção para a venda no mercado doméstico.

Na economia brasileira, porém, os custos de produção dos bens exportados nem sempre são iguais aos custos da produção destinada ao mercado doméstico. $\mathrm{O}$ regime de drawback, por exemplo, isenta o exportador de impostos com os quais arcaria se optasse por destinar sua produção ao mercado interno. Há, ainda, linhas de financiamento às exportações ofertadas pelo BNDES cujas condições de custo e de prazo são mais vantajosas do que aquelas vigentes no sistema financeiro doméstico, representando uma redução de custos da produção exportada vis-à-vis à produção destinada ao mercado interno. Do mesmo modo, há receitas financeiras vinculadas à atividade exportadora e que não são apropriadas pela firma quando sua produção se destina ao mercado doméstico. A rentabilidade da atividade exportadora, por exemplo, é afetada pelo diferencial de juros de curto prazo interno e externo no âmbito das operações de Adiantamento de Contrato de Câmbio (ACC), de Pagamento Antecipado das Exportações (PAE), bem como de operações de equalização de taxas de juros (PROEX).

(3) Mesmo assumindo a validade da Lei do Preço Único, a decisão de exportar ou de produzir para o mercado doméstico antecede a equalização de preços, $E . P f^{*}=P f$, que decorre, exatamente, da arbitragem praticada pelos agentes a partir do diferencial de receitas obtidas no mercado interno e no mercado externo. Note que esse processo de arbitragem e a consequente equalização de preços consome uma parcela não desprezível de tempo em função da presença de contratos no âmbito das operações de comércio exterior e domésticas, além da presença de alguma inércia nas tomadas de decisões estratégicas da firma. 


\subsection{As receitas financeiras e fiscais vinculadas à atividade de exportação: a metodologia de cálculo do câmbio implícito}

Ao longo dos anos, foi construída, no Brasil, uma estrutura de mecanismos que garante receitas fiscais e financeiras associadas à atividade de exportação. Neste trabalho, propõe-se uma metodologia para calcular a taxa de câmbio real implícita das exportações dos setores CNAE a dois dígitos, dada por:

$$
\theta=\frac{E_{i}^{*} \cdot P_{i}^{*}}{P_{i}},
$$

onde $P_{i}^{*}=$ nível de preços do setor i no mercado internacional; $P_{i}=$ nível de preços do setor i no mercado doméstico; e $E_{i}^{*}=$ taxa de câmbio nominal implícita do setor i. O cálculo da taxa de câmbio real implícita por setor é relevante para se conhecer as diferenças de estímulos às exportações percebidas nos diversos setores de atividade econômica.

A taxa $E^{*}{ }_{i}$ em determinado período é calculada apenas para o caso das exportações vinculadas a todos ou a algum dos instrumentos de promoção das exportações. O cômputo da taxa $E^{*}{ }_{i}$ em determinado período se dá a partir da divisão da receita de exportação em moeda doméstica do setor $i$ pelo valor da exportação em moeda estrangeira do setor $i$ naquele período - frise-se que são desconsideradas, nesse cálculo, as exportações não vinculadas a alguma(s) das operações supracitadas. Para essa divisão, a receita de exportação em moeda doméstica do setor i é encontrada por meio da multiplicação do valor das exportações em moeda estrangeira do setor i pela taxa de câmbio nominal média do período em análise, acrescida dos ganhos em moeda doméstica de receitas financeiras e fiscais decorrentes das operações de promoção das exportações vinculadas às exportações às do setor $i$ no período em análise. Desse modo, a taxa de câmbio nominal implícita é a taxa de câmbio nominal acrescida da participação (share) dos ganhos financeiros e fiscais do setor no total das suas exportações relacionadas a todas ou a alguma das operações citadas.

Portanto, a taxa de câmbio nominal implícita do setor $i, E_{i}^{*}$, é mais elevada do que a taxa de câmbio nominal. Vale dizer, $E_{i}^{*}>E$ (taxa de câmbio nominal), visto que aquela taxa reflete o aumento da receita de exportação proporcionado pelos ganhos financeiros e fiscais potenciais. Quanto maiores forem esses ganhos no setor $i$, maior será sua taxa de câmbio nominal implícita e maior será a diferença entre as taxas de câmbio $E^{*}{ }_{i}$ e $E$. Assim sendo, $E^{*}{ }_{i}$ é a verdadeira taxa de câmbio nominal com a qual os exportadores do setor $i$ que realizam alguma(s) das operações supracitadas se deparam, já que incorpora os ganhos obtidos a partir dessas operações.

Formalmente, sendo $V i=$ valor em moeda doméstica dos ganhos financeiros e fiscais do setor $i$ associados à sua atividade de exportação, a taxa de câmbio nominal implícita do setor i é dada por: 


$$
E_{i}^{*}=\frac{E \cdot P_{i}^{*} \cdot Q_{i}+V_{i}}{P_{i}^{*} \cdot Q_{i}}=E+\frac{V_{i}}{P_{i}^{*} \cdot Q_{i}},
$$

onde $Q=$ quantidade exportada vinculada a todas ou a algumas das operações de financiamento; $i=$ setor CNAE a dois dígitos. O conjunto dos ganhos fiscais e financeiros associados à atividade de exportação não é igual para os vários setores CNAE, como também não é constante, alterando-se a cada ano. Portanto, para cada ano, há múltiplas taxas de câmbio quando se consideram os diversos setores da atividade econômica.

A seguir, os instrumentos de promoção das exportações no Brasil são apresentados em maior detalhe juntamente com a metodologia de cálculo da taxa de câmbio implícita associada a cada um desses instrumentos.

\subsection{Instrumentos de financiamento e metodologia}

\section{(a) Adiantamento de Contrato de Câmbio (ACC) e Pagamento Antecipado de Exportações (PAE)}

O ACC é uma antecipação de recursos em moeda nacional para uma operação de exportação futura. Isso possibilita ao exportador garantir recursos para a produção e comercialização de mercadorias a serem exportadas. Os recursos destinados aos ACCs são captados no mercado internacional e repassados ao exportador a taxas de juros próximas às internacionais (Libor + spread bancário), em geral menores do que aquelas praticadas domesticamente. Contudo, o exportador pode optar por realizar operações de arbitragem com os recursos do ACC em função do elevado diferencial entre as taxas de juros interna e externa. Esses ganhos potenciais podem ser vistos como um aumento da rentabilidade da atividade exportadora.

O PAE é um pagamento que o exportador recebe antecipadamente por suas exportações. Os recursos são antecipados por um agente externo (banco ou o próprio importador) à taxa de juros vigente no mercado financeiro internacional (em geral, Libor) acrescida do spread bancário. Segundo informações do Banco Central do Brasil (Bacen), o prazo do PAE pode chegar a até dez anos, sendo acessível apenas às empresas de grande porte. Os mecanismos através dos quais são gerados ganhos financeiros vinculados à atividade exportadora no âmbito das operações do PAE são os mesmos anteriormente apontados para o caso das operações de ACC.

A partir das informações sobre o valor, em dólares, dos ACCs, por setor de atividade, encontrou-se o valor em reais, fazendo-se uso da taxa de câmbio nominal média do período em análise. A partir desse valor, calculou-se o ganho potencial com arbitragem. Para esse cálculo, foram considerados juros compostos, sendo o capital dado pelo valor em reais do ACC e o período de capitalização dado pelo prazo médio 
das operações de ACCs, ponderado pela participação do valor contratado em cada setor CNAE no valor total contratado de ACCs em cada mês.

O ganho de arbitragem correspondeu ao diferencial entre a taxa de juros composta pela média aritmética da Selic e da taxa de captação para capital de giro praticada no sistema financeiro nacional, e a média mensal da Libor (6 meses) acrescida do spread cobrado pelos bancos que fazem a intermediação das operações, ou seja, média entre a Selic e a taxa para capital de giro menos a soma de Libor com spread.

Em seguida, as receitas com arbitragem em reais de cada setor CNAE foram adicionadas ao valor em reais das exportações vinculadas às operações de ACCs, em cada setor, em cada mês. $\mathrm{O}$ valor em reais dessas exportações foi obtido pelo produto do valor das exportações em dólares que originaram os ACCs pela taxa de câmbio média vigente à época da liquidação dos contratos de exportação em cada mês. Ou seja, utilizou-se o prazo médio das operações de ACCs do setor para encontrar a taxa de câmbio nominal à época da liquidação dos contratos de exportação.

A soma das receitas das exportações e da arbitragem de juros, em reais, foi dividida pelo valor das exportações em dólares vinculadas às operações de ACCs para cada setor CNAE em cada mês. Desse modo, encontrou-se a taxa de câmbio nominal implícita de cada setor CNAE $\left(E^{*} i\right)$ em cada mês.

Para calcular a taxa de câmbio nominal implícita anual de cada setor, tomouse a média aritmética das taxas de câmbio nominal implícitas, de cada mês, em cada setor. A variação percentual entre a taxa de câmbio nominal implícita anual e a taxa de câmbio nominal anual foi obtida dividindo-se a primeira pela taxa de câmbio nominal anual vigente nos períodos de liquidação dos contratos de exportação vinculados às operações de ACCs.

A taxa de câmbio nominal implícita, na forma como está calculada na próxima seção, está associada, então, à receita total, em reais, proporcionada pelas exportações que estavam vinculadas a operações com $\mathrm{ACC}_{\mathrm{S}}$, e não à receita total, em reais, das exportações totais de cada setor CNAE em cada $\mathrm{ano}^{4}$.

A metodologia de cálculo da receita financeira do exportador proveniente do PAE é semelhante àquela apresentada para o caso do ACC. Em ambos os casos, o exportador recebe um montante, em reais, que corresponde a um adiantamento do valor que será exportado. Portanto, assim como no caso do ACC, calculou-se o ganho de arbitragem com juros do exportador. Para esse cálculo, foram considerados juros compostos, sendo o capital dado pelo valor em reais do PAE. Entretanto, o Bacen

(4) Visto que se objetiva conhecer o ganho cambial (isto é, a diferença entre a taxa de câmbio nominal implícita e a taxa de câmbio nominal) que o exportador alcança quando realiza ACC, optou-se por considerar o denominador da fórmula de $\mathrm{Ei}^{*}, E_{i}^{*}=E+\frac{V_{i}}{P_{i}^{*} \cdot Q_{i}}$ como o valor das exportações vinculadas a operações de ACC. 
não possui as informações sobre o prazo médio por setor CNAE das operações de PAE. Na ausência dessa informação, considerou-se que o período de capitalização dos recursos do PAE foi o mesmo obtido nos ACCs para cada setor CNAE ${ }^{5}$. Sendo a metodologia de cômputo da receita financeira com ACCs a mesma adotada para o PAE, optou-se, neste trabalho, por calcular a receita financeira agregada das operações de ACC e PAE por setor CNAE.

\section{e PAE:}

Duas considerações devem ainda ser feitas a respeito das operações de ACC

i) nem sempre são os exportadores que tomam o ACC. Isso decorre da existência do comércio de performance de exportação entre empresas regularizado pelo Banco Central, implicando desvio de recursos para atividades não exportadoras. Nesse mercado, o exportador vende seu produto para aquele que realizou a operação de ACC, e a exportação se realiza em nome do comprador da performance, que não é necessariamente uma firma exportadora. Contudo, como se trata de um mercado de balcão, onde as negociações geralmente ocorrem entre empresas e corretoras de câmbio, não sendo registradas contabilmente, não é possível mensurar sua dimensão (Rossi; Prates, 2009; Blumenschein; Leon, 2002; Veiga; Iglesias, 2000). O mercado de performance, portanto, não foi considerado neste trabalho para fins de cálculo dos ganhos financeiros dos exportadores com operações de ACC, o que pode ter acarretado uma possível superestimação desses ganhos, devendo o leitor interpretar os resultados com a devida cautela.

ii) as operações de ACC e PAE estão condicionadas ao embarque de uma mercadoria. Caso contrário, a empresa deve devolver o empréstimo com correção, anulando o ganho financeiro obtido, além de incorrer no pagamento de altos encargos ao Banco Central e na perda de sua credibilidade no mercado frente a uma nova contratação de crédito de ACC/PAE (Blumenschein; Leon, 2002). Contudo, a perda de ganhos financeiros e os encargos decorrentes de cenários de não embarque de mercadorias atrelados a operações de ACC e PAE não foram contemplados no cálculo da receita financeira do exportador. Isso se deu pela necessidade de facilitar e viabilizar as informações fornecidas pelo Banco Central, além do fato de que ocorrências dessa natureza são marginais, segundo informação do Banco Central.

\section{(b) Operações de equalização de taxas de juros (PROEX)}

O Proex (Programa de Financiamento às Exportações) é o principal instrumento público de apoio às exportações brasileiras de bens, estando voltado para as micro, pequenas e médias empresas. O objetivo do instrumento é conceder ao financiador (ou refinanciador) dos exportadores a equalização de taxas de juros,

(5) Essa é uma opção bastante conservadora, que implica subestimação das receitas financeiras potenciais do exportador com esse mecanismo de financiamento. 
tornando os encargos financeiros domésticos compatíveis com aqueles praticados no mercado internacional. Portanto, a exportação é financiada pelas instituições financeiras estabelecidas no país ou no exterior, e o PROEX arca com parte dos encargos financeiros incidentes de forma a tornar as taxas de juros equivalentes às praticadas internacionalmente. .

O cálculo do ganho financeiro nas operações de equalização de taxas através do PROEX obedece à mesma metodologia dos instrumentos anteriores. O mecanismo de incentivo se dá por meio da emissão de Notas do Tesouro Nacional para equalizar as taxas de juros obtidas pelos exportadores no mercado doméstico e as praticadas no mercado internacional. Trata-se, portanto, de um mecanismo semelhante àqueles já mencionados.

\section{(c) EXIM pré-embarque}

O BNDES-Exim corresponde a linhas de financiamento às exportações concedidas pelo Banco Nacional de Desenvolvimento Econômico e Social (BNDES) por intermédio de instituições financeiras credenciadas nas seguintes modalidades: Fase Pré-embarque (financiamento à produção) e Fase Pós-embarque (financiamento à comercialização). Em ambas as fases, as condições de custo e de prazo do financiamento são mais favoráveis do que aquelas vigentes no mercado doméstico ${ }^{6}$.

O cálculo da receita financeira do exportador proveniente das diversas operações de financiamento do BNDES (Pré-embarque), em suas diversas modalidades, também segue o padrão daquele realizado para o ACC e PAE ${ }^{7}$. Nesse mecanismo, o prazo de financiamento é mais curto, e o objetivo é garantir ao exportador recursos para viabilizar o embarque da mercadoria exportada. $\mathrm{O}$ exportador recebe um montante em reais adiantado pelo BNDES e seus intermediários financeiros.

O pagamento antecipado de suas exportações cria para o exportador a oportunidade de ganhos de arbitragem entre os juros cobrados pelo BNDES nas operações de Exim Pré-embarque e aqueles praticados no mercado doméstico (Selic). Portanto, assim como no ACC e no PAE, calculou-se o ganho de arbitragem com juros do exportador. Para esse cálculo, consideraram-se juros compostos, sendo o capital dado pelo valor em reais do financiamento do BNDES.

(6) As taxas de juros incidentes sobre os financiamentos do BNDES são a TJLP ou Libor + Spread do BNDES (entre 1\%, 2,5\% e 3\%) + Spread do intermediário financeiro.

(7) No financiamento das operações de pós-embarque, o objetivo é apoiar a comercialização no exterior dos bens já exportados, e o prazo máximo do financiamento é de 12 (doze) anos. Nesse caso, como é necessário que a exportação já tenha ocorrido, e em se tratando de um financiamento de longo prazo, a metodologia aqui proposta de cálculo do câmbio implícito não faz sentido. 
Uma vez obtida a capitalização dos recursos do Exim por meio de juros compostos, o restante da metodologia do cálculo da taxa de câmbio implícita por setor CNAE é idêntico à metodologia aplicada ao ACC.

\section{(d) O regime de Drawback}

O regime aduaneiro especial de drawback consiste na suspensão ou eliminação de tributos incidentes sobre insumos importados para a produção de bens exportados. O mecanismo reduz os custos de produção de produtos exportáveis, tornando-os mais competitivos no mercado internacional. De acordo com informações do Ministério do Desenvolvimento Indústria e Comércio (MDIC), o drawback é um importante mecanismo de incentivo às exportações. Historicamente, cada dólar importado sob o regime esteve associado a cinco dólares em exportações.

Recentemente, em 2008, o MDIC criou o Drawback Verde-Amarelo. Esse novo mecanismo ampliou a suspensão dos tributos prevista no drawback também para insumos e matérias-primas adquiridos no mercado doméstico. Assim, eliminouse a assimetria de custos dos insumos nacionais e importados para o exportador, que criava um viés em favor dos produtores estrangeiros. De acordo com estimativas do MDIC, com o Drawback Verde-Amarelo, as indústrias exportadoras deixam de carregar um custo que varia entre $4 \%$ e $6 \%$ de suas exportações totais por cerca de seis meses. Para empresas com alto coeficiente exportador que compram mais de 90\% dos insumos no mercado doméstico, o MDIC avalia que o crédito tributário pode chegar a $10 \%$ do valor das exportações (MDIC, 2008).

O cálculo setorial dos ganhos oriundos no âmbito do drawback não é trivial. Do ponto de vista da isenção do imposto sobre importações, a estimativa da variação cambial correspondente é impraticável, uma vez que não se pode estimar com precisão qual a participação dos insumos importados no total de insumos e matériasprimas utilizados na produção para a exportação. Contudo, é possível estimar o impacto do mecanismo em termos de suspensão tributária de PIS/IPI/COFINS, uma vez que os insumos importados têm tributos suspensos e os nacionais geram créditos tributários que são utilizados pelas empresas posteriormente. Assim, a partir do valor das exportações sujeitas ao drawback, pode-se estimar o total de suspensão de tributos de cada setor. Desde 2008, essa estimativa passa a representar o valor total da isenção tributária, uma vez que o Drawback Verde-Amarelo está em vigor.

A metodologia de cálculo, no que concerne à variação cambial correspondente ao ganho do exportador, guarda relação com os mecanismos descritos anteriormente. A diferença fundamental consiste no fato de que, no caso do drawback, o benefício é obtido imediatamente com a suspensão do pagamento dos tributos, e não com ganhos de arbitragem. 
Para estimar o valor dos tributos suspensos para cada setor, foi necessário, inicialmente, obter o percentual de matérias-primas e insumos intermediários utilizados em cada setor em relação à sua receita total. Esse percentual foi calculado utilizando informações da Pesquisa Industrial Anual (PIA) disponíveis para o ano de $2006^{8}$. Os percentuais de insumos e matérias-primas setoriais foram, então, multiplicados pelo valor das exportações sujeitas ao regime de drawback de cada setor de acordo com as informações obtidas junto ao $\mathrm{MDIC}^{9}$.

Finalmente, para calcular o valor dos tributos suspensos, foi necessário obter uma estimativa da alíquota acumulada de PIS, IPI e COFINS para os setores considerados. Para tal, foram utilizadas informações de uma simulação do DECEX, que evidenciou que a alíquota acumulada pode variar entre 12,11\% e 17,71\% (MDIC, 2008). Neste trabalho, foi considerado um valor médio de $15 \%$ para todos os setores nos quais os valores das exportações foram informados, entre 2006 e 2008, pelo MDIC. O resultado do produto do valor gasto com matérias-primas e insumos, e a alíquota acumulada de $15 \%$ indica o valor dos tributos suspensos pelo regime de drawback.

\section{Evidências empíricas}

\subsection{ACC P PAE}

Os dados requeridos para o cálculo da taxa de câmbio implícita das exportações por setor CNAE associadas aos mecanismos de ACC e PAE foram fornecidos pelo Banco Central do Brasil para o período de janeiro de 2004 a agosto de 2008. Os valores das operações de ACC e PAE realizadas pela CNAE a dois dígitos nesse período são muito heterogêneos e concentrados em poucos setores. Apenas nove setores realizaram operações cujos valores representaram entre $78 \%$ e $80 \%$ do valor total das operações com esses instrumentos financeiros nos anos de 2004 a 2008 (Tabela 1) $^{10}$. Esses setores são: Extração de Minerais Metálicos, Fabricação de Produtos Alimentícios, Fabricação de Produtos do Fumo, Fabricação de Celulose, Papel e Produtos de Papel, Fabricação de Produtos Químicos, Metalurgia, Fabricação de Máquinas e Equipamentos, Fabricação de Veículos Automotores, Reboques e Carrocerias, Comércio por Atacado Exceto Veículos Automotores e Motocicletas.

Destacam-se os setores de Fabricação de Produtos Alimentícios, Comércio por Atacado Exceto Veículos Automotores e Motocicletas e Metalurgia com cerca de $22 \%, 15 \%$ e $10 \%$, respectivamente, do valor total do conjunto das operações de

(8) O percentual médio na indústria de transformação no ano de referência foi cerca de $46 \%$, apresentando grande variabilidade setorial, entre $9 \%$ no setor de extração de minerais não ferrosos e $78,3 \%$ no setor de moagem de café.

(9) Adota-se o pressuposto de que a produção destinada às exportações segue o mesmo processo descrito pela PIA.

(10) Há 83 setores CNAE a dois dígitos. 
ACC e PAE verificadas durante o período citado. O setor de Extração de Minerais Metálicos chama a atenção pela elevada variância dos valores entre 2004 e 2008 . $\mathrm{Na}$ média do período em análise, esse setor participou com 9,3\% do valor total do conjunto das operações de ACC e PAE.

\section{Tabela 1}

ACC e PAE: Participação setorial no valor total das operações (\%)

\begin{tabular}{lccccc}
\hline Setor CNAE & 2004 & 2005 & 2006 & 2007 & 2008 \\
\hline Fab. de prod. alimentícios & 23,3 & 20,9 & 19,2 & 23,3 & 24,9 \\
Com. por atacado, ex. veículos automotores & 18,5 & 17,3 & 15,4 & 12,8 & 16,0 \\
Metalurgia & 10,8 & 12,2 & 9,8 & 9,9 & 13,1 \\
Extração de minerais metálicos & 1,8 & 5,2 & 15,2 & 16,4 & 8,1 \\
Fab. de prod. do fumo & 4,1 & 3,5 & 2,7 & 2,6 & 4,4 \\
Fab. de máquinas e equip. & 5,5 & 5,2 & 4,1 & 3,3 & 4,1 \\
Fab. de celulose, papel e prod. de papel & 2,6 & 5,0 & 4,7 & 3,5 & 3,4 \\
Fab. de veículos automotores & 7,7 & 7,7 & 5,0 & 3,5 & 3,1 \\
Fab. de coque, de prod. derivados do petróleo & 0,7 & 0,6 & 0,9 & 2,1 & 3,0 \\
Fab. de prod. químicos & 3,8 & 3,2 & 4,2 & 4,1 & 3,0 \\
Fab. de outros equip. de transp, ex. veículos & 1,8 & 2,6 & 3,0 & 1,7 & 2,3 \\
$\quad$ automotores & 1,9 & 0,9 & 1,1 & 3,1 & 2,2 \\
Ativ. de serviços financeiros & 3,7 & 2,9 & 2,7 & 2,6 & 2,0 \\
Prep. de couros e fab. de couro e calçados & 13,8 & 12,8 & 12,0 & 11,0 & 10,4 \\
Outros setores & 100,0 & 100,0 & 100,0 & 100,0 & 100,0 \\
\hline Total & & &
\end{tabular}

Fonte: Elaboração própria a partir de informações do Banco Central do Brasil e IPEA.

A Tabela 2 apresenta a variação percentual entre a taxa de câmbio implícita, que decorre dos ganhos financeiros provenientes do conjunto de operações de ACC e PAE, e a taxa de câmbio nominal para setores CNAE selecionados entre 2004 e 2008. Para o total das atividades de exportação, a taxa de câmbio implícita foi superior à taxa de câmbio nominal em 6,4\% em 2004. O menor diferencial entre essas taxas ocorreu em 2007, quando o aumento percentual da taxa de câmbio foi de $3,7 \%$. Destaca-se, ainda, a forte redução do diferencial cambial entre o biênio 20042005 e o triênio 2006-2008 observada em função da redução da diferença entre a taxa de juros composta pela Selic e pela taxa de capital de giro, de um lado, e a taxa dada pela Libor acrescida de um spread, de outro, entre o segundo semestre de 2005 e o segundo semestre de 2007.

Para as operações de ACC e PAE, a diferença percentual entre a taxa de câmbio implícita e a taxa de câmbio nominal em determinado setor CNAE depende de três fatores, ou seja, o diferencial de juros presente no âmbito das operações de arbitragem, o prazo médio dessas operações e a participação do valor das operações de ACC e PAE no valor das exportações vinculadas a essas operações. Esses três fatores se modificam ao longo dos anos em um mesmo setor e são muito heterogêneos entre os setores. Portanto, embora essas operações estejam concentradas em nove setores, 
anteriormente elencados, (Extração de Minerais Metálicos; Fabricação de Produtos Alimentícios; Fabricação de Produtos do Fumo; Fabricação de Celulose, Papel e Produtos de Papel; Fabricação de Produtos Químicos; Metalurgia; Fabricação de Máquinas e Equipamentos; Fabricação de Veículos Automotores, Reboques e Carrocerias; Comércio por Atacado Exceto Veículos Automotores e Motocicletas), a diferença percentual entre as taxas de câmbio implícita e nominal nos setores CNAE não será necessariamente mais elevada nesses mesmos setores.

Quanto ao diferencial de juros, há uma mudança entre os setores apenas em função das diferenças nos spreads cobrados pelo intermediário financeiro nas operações de ACC e PAE (a arbitragem de juros depende da diferença entre a média da Selic e da taxa de capital de giro, e da Libor acrescida do spread). Sendo assim, é principalmente a combinação, em cada setor, do prazo médio das citadas operações com a participação do valor das mesmas no valor total das exportações vinculadas às operações de ACC e PAE que determinará o aumento percentual da taxa de câmbio setorial quando os ganhos financeiros decorrentes dessas operações são incorporados no cálculo da taxa de câmbio (implícita) de cada setor.

Tabela 2

ACC e PAE: Diferença percentual entre a taxa de câmbio implícita e a taxa de câmbio nominal (\%)

\begin{tabular}{|c|c|c|c|c|c|}
\hline Setor CNAE & 2004 & 2005 & 2006 & 2007 & $2008^{*}$ \\
\hline \multicolumn{6}{|l|}{ Setores com as maiores diferenças percentuais } \\
\hline Outras atividades profissionais, científicas e técnicas & 16,55 & 11,53 & 11,89 & 4,83 & 5,23 \\
\hline Fabricação de produtos do fumo & 15,74 & 17,13 & 10,75 & 7,61 & 6,65 \\
\hline Atividades de organizações associativas & 11,46 & 7,01 & 8,73 & 9,39 & 4,05 \\
\hline Pesquisa e desenvolvimento científico & 10,22 & 7,99 & 10,23 & 7,8 & 4,91 \\
\hline Fabricação de produtos alimentícios & 7,11 & 6,85 & 4,67 & 4,88 & 4,35 \\
\hline $\begin{array}{l}\text { Preparação de couros e fabricação de artefatos de couro, } \\
\text { artigos para viagem e calçados }\end{array}$ & 6,83 & 6,41 & 4,37 & 4,21 & 3,82 \\
\hline Agricultura, pecuária e serviços relacionados & 6,28 & 5,9 & 5,04 & 3,16 & 3,83 \\
\hline Fabricação de produtos de minerais não metálicos & 5,25 & 5,86 & 4,23 & 4,36 & 3,43 \\
\hline fabRicação de produtos de madeira & 5,09 & 5,74 & 4,32 & 4,17 & 4,03 \\
\hline \multicolumn{6}{|l|}{ Setores com as menores diferenças percentuais } \\
\hline \multirow{2}{*}{$\begin{array}{l}\text { Fabricação de produtos farmoquímicos e farmacêuticos } \\
\text { Fabricação de coque, de produtos derivados do petróleo }\end{array}$} & 2,24 & 1,6 & 1,72 & 1,11 & 0,43 \\
\hline & 2,21 & 1,11 & 1,18 & 1,42 & 2,13 \\
\hline $\begin{array}{l}\text { Fabricaçã̃o de equipamentos de informática, produtos } \\
\text { eletrônicos e ópticos }\end{array}$ & 1,77 & 0,84 & 0,62 & 0,61 & 0,32 \\
\hline Alimentação & 0,99 & 0,04 & 0,19 & 0,34 & 0,52 \\
\hline \multirow{2}{*}{$\begin{array}{l}\text { Publicidade e pesquisa de mercado } \\
\text { Manutenção, reparação e instalação de máquinas e }\end{array}$} & 0,66 & 0,16 & 0,26 & 0,39 & 0,22 \\
\hline & 0,46 & 1,08 & 0,22 & 0,29 & 1,51 \\
\hline $\begin{array}{l}\text { Atividades auxiliares dos serviços financeiros, seguros, } \\
\text { previdência complementar e planos de saúde }\end{array}$ & 0,45 & 0,11 & 0,37 & 0,07 & 0,04 \\
\hline Atividades dos serviços de tecnologia da informação & 0,05 & 0,07 & 0,06 & 0,07 & 0,23 \\
\hline Atividades jurídicas, de contabilidade e de auditoria & 0 & 1,2 & 0,05 & 0,02 & 0,02 \\
\hline Total & $6,37 \%$ & $5,98 \%$ & $3,99 \%$ & $3,73 \%$ & $3,89 \%$ \\
\hline
\end{tabular}

Fonte: Elaboração própria a partir de informações do Banco Central do Brasil e IPEA. * para o ano de 2008, os dados referem-se aos meses de janeiro a agosto. 
No caso da indústria e da agropecuária, o setor com maior aumento percentual da taxa de câmbio foi o de Fabricação de Produtos do Fumo. Nesse caso, a taxa de câmbio implícita do setor foi, em média, 11,58\% superior à taxa de câmbio nominal para os anos da série estudada, 2004-2008. Variações cambiais entre 4\% e 7\% foram verificadas no setor de Fabricação de Produtos Alimentícios entre 2004 e 2008. Nos setores de Preparação de Couros, Fabricação de Artefatos de Couro, Artigos para Viagem e Calçados, Fabricação de Produtos de Madeira, Agricultura, Pecuária e Serviços Relacionados e Fabricação de Produtos Minerais Não Metálicos, a faixa de variação cambial situou-se entre $3,43 \%$ e 6,83\% nesse período. Em relação a serviços, o setor Outras Atividades Profissionais Científicas e Técnicas apresentou um diferencial médio da taxa de câmbio de 10\%, seguido dos setores Atividades de Organizações Associativas e Pesquisa e Desenvolvimento Científico com um diferencial cambial cuja média, para o período 2004-2008, foi superior a $8 \%$.

Os setores produtivos que apresentaram os menores diferenciais entre a taxa de câmbio implícita e a taxa de câmbio nominal, entre 2004 e 2008, foram os de Manutenção, Reparação e Instalação de Máquinas e Equipamentos, Fabricação de Equipamentos de Informática, Produtos Eletrônicos e Ópticos, Fabricação de Produtos Farmoquímicos e Farmacêuticos e Fabricação de Coque, de Produtos Derivados do Petróleo e de Biocombustíveis com o citado diferencial entre $0,22 \%$ e $2,24 \%$.

Para os serviços, os setores Alimentação, Atividades dos Serviços de Tecnologia da Informação, Atividades Auxiliares dos Serviços Financeiros, Seguros, Previdência Complementar e Planos de Saúde, Atividades Jurídicas, de Contabilidade e Auditoria, assim como Publicidade e Pesquisa de Mercado apresentaram um aumento da taxa de câmbio entre 0,0\% e 0,99\% entre 2004 e 2008.

\subsection{Drawback}

Tendo em vista que o regime de drawback se constitui em uma medida de incentivo às exportações através da isenção do IPI/PIS/Cofins, é possível estimar uma taxa de câmbio (implícita) compatível com a isenção fiscal prevista nesse modelo. Conforme nota técnica (NT7/2008) do Ministério do Desenvolvimento, Indústria e Comércio Exterior (MDIC), o Drawback Verde-Amarelo, uma modalidade particular de instrumento, permite uma suspensão de impostos em torno de $4 \%$ a $6 \%$ do valor total das exportações industriais brasileiras.

Na prática, o valor da variação cambial correspondente ao drawback pode ser obtido pela multiplicação do percentual gasto com insumos e matérias-primas em 
cada setor pela alíquota acumulada de IPI/PIS/COFINS. Isso ocorre porque o valor do percentual de matérias-primas só pode ser calculado até o ano de 2006, último ano para o qual a PIA está disponível. Esse valor foi usado também para os anos de 2007 e 2008. Os valores para os três anos foram incluídos, uma vez que nem todos os setores exportaram em todos os anos da série ${ }^{11}$. Além disso, para que o valor total da variação cambial pudesse ser calculado de maneira apropriada, foi necessário ponderar os percentuais setoriais pelos respectivos valores exportados.

As estimativas da taxa de câmbio implícita que decorre do regime de drawback para o setor CNAE a 2 dígitos tiveram como fonte de dados o MDIC/ SECEX e a PIA/IBGE, ressaltando-se que há dados disponíveis apenas para o período 2006-2008. Conforme a Tabela 3, o câmbio médio implícito de 2006 a 2008 foi da ordem de $7 \%$ acima da taxa de câmbio média para esses anos. O câmbio implícito envolvido em operações de Drawback é diferente por setor, o que depende não só do volume exportado, mas também da participação de insumos e matérias-primas em sua receita total. Conforme a Tabela 3 , os setores cuja variação cambial foi superior à média global da indústria apresentaram ganhos cambiais que, em alguns casos, superaram os 10\%, a exemplo de Máquinas e Aparelhos Elétricos.

Contudo, como pode ser visto na segunda metade da tabela, apenas alguns setores combinam o câmbio implícito elevado com uma participação também elevada no total de tributos suspensos. Esses são setores-chave, como Fabricação de Veículos Automotores, Metalurgia, Outros Equipamentos de Transporte e Alimentos.

Alternativamente, alguns setores apresentam menor rentabilidade ao utilizarem o instrumento de Drawback, em parte como consequência das dificuldades em obter insumos domésticos (baixo grau de substitutibilidade) e devido ao fato de que as exportações, elas próprias, são de insumos básicos. Esse é o caso de Extração de Petróleo e Gás Natural, Extração de Minerais Metálicos e Não Metálicos e Fabricação de Máquinas e Equipamentos.

Finalmente, dois pontos devem ser ressaltados. Em primeiro lugar, as estimativas apresentadas na tabela 3 são subestimadas entre 2006 e 2008, uma vez que o valor da isenção do imposto sobre importações não entra no cálculo. Em segundo lugar, no mesmo período, a suspensão dos tributos sobre insumos e matérias-primas nacionais estava associada ao custo financeiro de carregar o crédito tributário permitido pelo regime do drawback. De acordo com as estimativas do MDIC (2008), esse custo financeiro varia entre 4\% e $6 \%$ das exportações totais. Assim, a partir dessa perspectiva, existe uma tendência de sobre-estimar a variação

(11) O cálculo também pressupõe que dentro do mesmo setor empresas exportadoras e aquelas que produzem para o mercado doméstico possuam a mesma estrutura de custos. 
cambial ligada à parcela nacional dos insumos e matérias-primas. Contudo, esse custo tenderia a desaparecer, a partir de 2009, com a implementação do Drawback Verde-Amarelo.

Tabela 3

Drawback: diferença entre o câmbio implícito e o câmbio nominal e participação no total de tributos suspensos - setores acima do total ponderado

\begin{tabular}{lccc|ccc}
\hline Setor CNAE & \multicolumn{3}{c}{ Var. Cambial } & \multicolumn{3}{c}{ \% Susp. Tributos } \\
\cline { 2 - 7 } & 2006 & 2007 & 2008 & 2006 & 2007 & 2008 \\
\hline Fab. de máquinas, aparelhos e materiais elétricos & 10.1 & 10.1 & 9.3 & 0.1 & 0.1 & 0.0 \\
Fab. de prod. alimentícios & 9.0 & 9.0 & 9.0 & 1.0 & 1.4 & 2.0 \\
Fab. de veículos autom. reboques e carrocerias & 8.6 & 8.6 & 8.6 & 5.9 & 5.0 & 3.9 \\
Fab. de prod. químicos & 8.1 & 8.1 & 8.1 & 0.5 & 0.6 & 0.5 \\
Prep. de couros e fab. de de couro e calçados & 7.9 & 7.9 & 7.9 & 2.0 & 2.4 & 1.6 \\
Fab. de prod. de borracha e de material plástico & 7.7 & 7.7 & 7.7 & 1.1 & 1.3 & 1.1 \\
Metalurgia & 7.3 & 7.3 & 7.3 & 4.0 & 4.2 & 3.1 \\
Fab. prod. fumo & 7.3 & 7.3 & 7.3 & 0.3 & 0.1 & 0.3 \\
Fab. de prod. têxteis & 7.2 & 7.2 & 7.2 & 0.2 & 0.2 & 0.2 \\
Confecção de artigos do vestuário e acessórios & 7.2 & 7.2 & 7.2 & 0.0 & 0.0 & 0.0 \\
Fab. de outros equip. de transp., ex. veículos & 7.1 & 7.1 & 7.1 & 2.3 & 2.8 & 2.8 \\
Fab. de máquinas, aparelhos e materiais elétricos & 7.3 & 6.9 & 6.9 & 0.3 & 0.3 & 0.2 \\
Fab. de móveis & 6.9 & 6.9 & 6.9 & 0.6 & 0.4 & 0.5 \\
Fab. de equip. de informática, prod. eletrônicos & 7.2 & 6.7 & 6.7 & 1.0 & 0.7 & 1.3 \\
Fab. de prod. de metal, exceto máquinas & 6.5 & 6.5 & 6.5 & 0.1 & 0.2 & 0.2 \\
Fab. de prod. de madeira & 6.2 & 6.2 & 6.2 & 0.3 & 0.3 & 0.4 \\
Fab. de celulose, papel e prod. de papel & 6.0 & 6.0 & 6.0 & 1.1 & 0.8 & 1.0 \\
Coleta, tratamento e disp. de resíduos & 5.1 & - & 5.1 & 0.0 & 0.0 & 0.0 \\
Fab. de prod. de minerais não metálicos & 5.0 & 5.0 & 5.0 & 0.4 & 0.2 & 0.4 \\
Impressão e reprodução de gravações & 4.6 & 4.6 & 4.6 & 0.0 & 0.0 & 0.0 \\
Fab. de máquinas e equipamentos & 5.1 & 5.1 & 4.4 & 0.0 & 0.1 & 0.0 \\
Extração de minerais não metálicos & 4.3 & 4.3 & 4.3 & 0.2 & 0.2 & 0.2 \\
Extração de petróleo e gás natural & 1.7 & 1.8 & 1.8 & 0.0 & 0.0 & 0.0 \\
Extração de minerais metálicos & 1.8 & 1.8 & 1.8 & 1.8 & 1.5 & 2.3 \\
\hline Total & 6.9 & 7.0 & 6.9 & 100.0 & 100.0 & 100.0 \\
\hline
\end{tabular}

Nota: Total agregado ponderado pelas exportações setoriais.

Fonte: Elaboração própria a partir de dados do MDIC/Secex e PIA/IBGE.

\subsection{PROEX}

A variação percentual entre a taxa de câmbio implícita, que resulta dos ganhos financeiros com equalização de taxas de juros no âmbito do PROEX, e a taxa de câmbio nominal está apresentada, em nível setorial, na tabela 4. A fonte de dados para o cálculo dessa taxa de câmbio implícita foi o Banco do Brasil.

As operações de equalização de taxas de juros permitiram um ganho médio em torno de 5\% além da taxa de câmbio nominal no período 2004-2008. O câmbio implícito obtido em alguns setores atingiu aproximadamente 20\% em 2004 e 2005 (como em Eletricidade, Gás e Outras Utilidades), períodos em que a taxa de juros 
básica do Banco Central era muito mais alta em relação àquela verificada nos anos seguintes. Conforme se constata na Tabela 4, poucos setores se beneficiaram desse instrumento de incentivo.

Tabela 4

PROEX: Diferença percentual entre a taxa de câmbio implícita e a taxa de câmbio nominal (\%)

\begin{tabular}{lccccc}
\hline Setor CNAE & 2004 & 2005 & 2006 & 2007 & 2008 \\
\hline Outros & 10,4 & 10,2 & 10,1 & 8,8 & 6,9 \\
Preparação de couros e fabricação de artefatos de couro, & 0,2 & 0,2 & - & - & - \\
$\quad$ artigos para viagem e calçados & - & - & - & - & 0,1 \\
Fabricação de produtos químicos & - & - & - & - & - \\
Fabricação de máquinas, aparelhos e materiais elétricos & 11,0 & - & 0,9 & 0,9 & - \\
Fabricação de máquinas e equipamentos & 0,9 & 9,7 & 4,9 & 5,6 \\
Fabricação de veículos automotores, reboques e & 3,4 & 4,8 & 4,7 & 5,6 & 5,9 \\
$\quad$ carrocerias & 1,8 & 1,8 & 1,9 & 2,0 & 1,9 \\
Fabricação de móveis & - & - & - & 0,2 & 0,2 \\
Fabricação de produtos diversos & 3,6 & 3,8 & 4,7 & 4,0 & 3,1 \\
Fabricaçao e montagem de veiculos automotores, & 19,7 & 19,4 & 13,6 & 9,8 & 4,9 \\
$\quad$ reboques e carrocerias & 6,9 & 5,0 & 5,2 & 4,8 & 5,0 \\
Eletricidade, gás e outras utilidades & & & & \\
\hline Total
\end{tabular}

Nota: Total ponderado pelo valor equalizável (Dados fornecidos pela NCM e traduzido para o CNAE $1.0)$.

Fonte: Elaboração própria com informações do Banco do Brasil/MDIC.

\subsection{EXIM}

Os resultados dos financiamentos Exim Pré-embarque do BNDES revelam um fenômeno distinto das operações até aqui analisadas. O ganho de arbitragem possibilitado com essas operações chegou a valores significativos em todos os anos considerados. A partir da estimação do câmbio implícito segundo os ganhos alcançados por meio dos financiamentos do Exim Pré-embarque, constatou-se que a diferença percentual entre a taxa de câmbio implícita e a taxa de câmbio nominal nos anos do quadriênio 2004-2007 foi, em geral, de mais de 12\%, elevando-se substancialmente após esse período e alcançando uma média de mais de $25 \% \mathrm{em}$ 2008 (Tabela 5). A fonte de dados para o cálculo do câmbio implícito foi o BNDES.

Esse resultado atípico decorre do fato de que o BNDES não fornece o total de exportações de cada setor, mas tão somente o total de liberações de recursos usados nos financiamentos. Com isso, a metodologia adotada não pondera o total liberado pelo total de exportações, e admite-se, portanto, para o cálculo do câmbio implícito, que o total financiado coincide com o total das exportações, o que produz uma sobre-estimativa da taxa de câmbio implícita. 
Tabela 5

EXIM: Diferença percentual entre a taxa de câmbio implícita e a taxa de câmbio nominal (\%)

\begin{tabular}{|c|c|c|c|c|c|}
\hline Setor CNAE & 2004 & 2005 & 2006 & 2007 & $2008^{*}$ \\
\hline Ativ. de sedes de empresas e de consult. gestão & 12.0 & 18.0 & 10.2 & - & 52.9 \\
\hline \multirow{2}{*}{$\begin{array}{l}\text { Confecção de artigos do vestuário e acessórios } \\
\text { Fab. de outros equip. de transporte, exceto } \\
\text { automotores }\end{array}$} & 14.0 & 15.0 & 11.9 & - & 51.3 \\
\hline & 5.8 & 9.1 & 13.5 & 8.3 & 42.9 \\
\hline Fab. de prod. de metal, exceto máq. e equip. & 12.5 & 19.1 & 11.1 & 8.6 & 39.8 \\
\hline Prep. de couros e fab. de artef. de couro, calçados & 10.8 & 17.3 & 13.5 & 12.1 & 37.4 \\
\hline Fab. de equip. de inf., prod. eletrônicos e ópticos & 8.7 & 12.4 & 11.7 & 8.7 & 35.6 \\
\hline Fab. de prod. químicos & 11.5 & 19.0 & 15.0 & 11.1 & 30.6 \\
\hline Fab. de prod. de minerais não metálicos & 11.0 & 16.7 & 13.2 & 11.1 & 30.0 \\
\hline Metalurgia & 12.3 & 19.3 & 15.2 & - & 29.4 \\
\hline Fab. de prod. alimentícios & 11.2 & 14.3 & 12.0 & 9.8 & 26.3 \\
\hline Fab. de veículos automotores, reboques e carrocerias & 11.2 & 17.2 & 13.5 & 10.9 & 25.2 \\
\hline Fab. de prod. têxteis & 8.7 & 15.2 & 14.3 & 10.6 & 24.2 \\
\hline \multirow{2}{*}{$\begin{array}{l}\text { Fab. de máq. e equip. } \\
\text { Com. por atacado, exceto veículos automotores e } \\
\text { moto }\end{array}$} & 12.4 & 17.3 & 14.6 & 10.0 & 24.2 \\
\hline & 9.8 & 15.9 & 13.6 & 11.3 & 23.6 \\
\hline Agricultura, pecuária e serviços relacionados & 10.5 & 15.2 & 14.0 & 10.6 & 21.1 \\
\hline Fab. de prod. farmoquímicos e farmacêuticos & 12.6 & - & - & - & 18.5 \\
\hline Fab. de prod. de borracha e de material plástico & 12.7 & 14.0 & 14.6 & 9.8 & 17.1 \\
\hline Fab. de máq., aparelhos e materiais elétricos & 11.2 & 15.7 & 14.2 & 10.8 & 16.8 \\
\hline Fab. de prod. diversos & 11.6 & 11.9 & 13.0 & - & 16.2 \\
\hline Com. e rep. de veículos automotores e motocicletas & - & - & - & - & 13.6 \\
\hline Fab. de prod. de madeira & 9.9 & 15.1 & 13.6 & 12.6 & 12.3 \\
\hline Fab. de móveis & 10.4 & 12.2 & 9.5 & 11.7 & 10.7 \\
\hline Captação, tratamento e distribuição de água & - & - & - & - & 9.0 \\
\hline Fab. de celulose, papel e prod. de papel & 16.5 & 17.4 & 6.3 & 7.3 & 8.7 \\
\hline Com. varejista & - & 15.6 & 14.1 & - & 4.7 \\
\hline Produção florestal & - & - & 10.4 & - & - \\
\hline Pesca e aqüicultura & 9.6 & 15.3 & - & 13.4 & - \\
\hline Extração de minerais não metálicos & 13.3 & - & - & 12.2 & - \\
\hline Fab. de bebidas & 16.5 & - & - & - & - \\
\hline Impressão e reprodução de gravações & 14.9 & - & - & - & - \\
\hline Eletricidade, gás e outras utilidades & - & - & - & 3.5 & - \\
\hline Telecomunicações & - & 19.1 & - & - & - \\
\hline Ativ. dos serviços de tecnologia da informação & - & - & - & 14.1 & - \\
\hline Ativ. de serviços financeiros & 6.4 & 18.2 & 10.1 & - & - \\
\hline Total ponderado & 10.3 & 16.2 & 13.2 & 9.8 & 25.4 \\
\hline
\end{tabular}

Nota: $\left.{ }^{*}\right)$ : valores do câmbio futuro dos contratos de 2008 consideram o câmbio nominal de dezembro de 2008 como referência.

Fonte: Elaboração própria a partir de dados do BNDES.

\subsection{Impacto agregado}

Entre os instrumentos de incentivo às exportações utilizados neste trabalho para o cálculo da taxa de câmbio implícito, o ACC e o PAE apresentaram, entre 2004 e 2008, a maior participação no total dos recursos que correspondem aos incentivos 
fiscais e financeiros vinculados à atividade de exportação no Brasil. O sistema de equalização do PROEX apresentou a menor participação, em torno de 3,5\% do total desses recursos (Tabela 6).

Tabela 6

Participação no total dos instrumentos de financiamento às exportações - 2004 a 2008

\begin{tabular}{lccccc}
\hline Valor (milhões de R \$ correntes) & 2004 & 2005 & 2006 & 2007 & 2008 \\
\hline ACC + PAE* & $108,819.5$ & $111,370.3$ & $106,467.5$ & $123,702.4$ & $78,884.7$ \\
Equalização PROEX & $4,177.7$ & $4,954.8$ & $8,166.0$ & $5,501.8$ & $6,420.3$ \\
Drawback & 0.0 & 0.0 & $16,124.8$ & $15,772.0$ & $16,069.5$ \\
EXIM Pré-Embarque & $5,477.2$ & $7,404.7$ & $9,799.4$ & $6,747.5$ & $9,554.7$ \\
Total & $118,474.3$ & $123,729.8$ & $140,557.8$ & $151,723.7$ & $110,929.2$ \\
\hline
\end{tabular}

Nota: (*) Valores de 2008 correspondentes ao período de janeiro a agosto.

Fonte: Elaboração própria a partir de dados do Bacen, BNDES e BB.

Tendo visto os efeitos dos diversos instrumentos de apoio às atividades exportadoras, assim como seu impacto setorial diferenciado, é feito, a seguir, um exercício teórico de cálculo da variação cambial agregada. É importante ressaltar que se trata de um exercício teórico, pois é improvável que os exportadores utilizem concomitantemente todos os instrumentos disponíveis. Para obter um indicador da variação cambial correspondente ao conjunto dos ganhos proporcionados por todos os instrumentos (ACC, PAE, Drawback, PROEX e Exim-Pré-BNDES) no período de 2004 a 2008, foi necessário estabelecer um fator de ponderação que refletisse a representatividade relativa de cada instrumento. Assim, os valores totais das liberações de ACC e PAE, o valor das equalizações do PROEX, os valores da isenção fiscal estimada referente ao Drawback e as liberações do Exim-Pré foram somados, permitindo, dessa forma, o cálculo do percentual de cada instrumento no total geral.

Como pode ser visto na Tabela 7, ACC e PAE são, em termos de valor, os principais instrumentos entre os quatro considerados. Assim, não é surpresa que a variação cambial referente aos ganhos com ACC e PAE dominem o total geral. Em segundo lugar, encontra-se o Drawback Verde-Amarelo que, nos períodos para os quais as informações estão disponíveis, representam um valor expressivo e crescente do total dos instrumentos.

A participação crescente do Drawback serviu para amortecer a queda da variação cambial correspondente aos outros instrumentos. Isso ocorre, como comentado anteriormente, devido ao fato de que os ganhos potenciais dos demais instrumentos dependem da diferença entre a taxa de juros com a qual o exportador toma o financiamento e a vigente no mercado doméstico. Como a Selic apresentou uma trajetória de queda no período, os ganhos potenciais diminuem, mesmo com o aumento progressivo do valor da soma de todos os instrumentos. Conforme a última linha da Tabela 7, os ganhos fiscais e financeiros proporcionados pelo conjunto das 
políticas de promoção de exportações resultaram em uma taxa de câmbio implícita superior em 6,5\% à taxa de câmbio no biênio 2004-2005. Em 2008, essa diferença alcançou $6,2 \%$.

Tabela 7

Instrumentos de incentivo: valor, participação percentual e variação cambial total

\begin{tabular}{lccccc}
\hline Valor (milhões R\$ correntes) & 2004 & 2005 & 2006 & 2007 & 2008 \\
\hline ACC + PAE* & $108,819.5$ & $111,370.3$ & $106,467.5$ & $123,702.4$ & $78,884.7$ \\
Equalização PROEX & $4,177.7$ & $4,954.8$ & $8,166.0$ & $5,501.8$ & $6,420.3$ \\
Drawback & 0.0 & 0.0 & $16,124.8$ & $15,772.0$ & $16,069.5$ \\
EXIM Pré-Embarque & $5,477.2$ & $7,404.7$ & $9,799.4$ & $6,747.5$ & $9,554.7$ \\
Total & $118,474.3$ & $123,729.8$ & $140,557.8$ & $151,723.7$ & $110,929.2$ \\
Participação no total & & & & & \\
\hline ACC + PAE & $91.9 \%$ & $90.0 \%$ & $75.7 \%$ & $81.5 \%$ & $71.1 \%$ \\
Equalização PROEX & $3.5 \%$ & $4.0 \%$ & $5.8 \%$ & $3.6 \%$ & $5.8 \%$ \\
Drawback & $0.0 \%$ & $0.0 \%$ & $11.5 \%$ & $10.4 \%$ & $14.5 \%$ \\
EXIM Pré-Embarque & $4.6 \%$ & $6.0 \%$ & $7.0 \%$ & $4.4 \%$ & $8.6 \%$ \\
Variação Cambial & & & & & \\
\hline ACC + PAE & $6.4 \%$ & $6.0 \%$ & $4.0 \%$ & $3.7 \%$ & $3.9 \%$ \\
Equalização PROEX & $4.1 \%$ & $4.1 \%$ & $4.3 \%$ & $4.2 \%$ & $4.6 \%$ \\
Drawback & $0.0 \%$ & $0.0 \%$ & $6.9 \%$ & $7.0 \%$ & $6.9 \%$ \\
EXIM Pré-Embarque & $10.3 \%$ & $16.2 \%$ & $13.2 \%$ & $9.8 \%$ & $25.4 \%$ \\
\hline Total ** & $6.5 \%$ & $6.5 \%$ & $5.0 \%$ & $4.4 \%$ & $6.2 \%$ \\
\hline Not & $*$ Va $\%$ & & \\
\hline
\end{tabular}

Nota: $(*)$ Valores de 2008 correspondentes ao período de janeiro a agosto.

(**) Total ponderado pelo valor total dos instrumentos.

Fonte: Elaboração própria a partir de dados do Bacen, BNDES e BB.

\section{Considerações finais}

No Brasil, há diversos instrumentos fiscais e financeiros que proporcionam redução de custos de produção e ganhos de receita financeira no âmbito da atividade de exportação. Ademais, o peso desses incentivos fiscais e financeiros na rentabilidade das exportações não é homogêneo entre os setores da economia. Neste trabalho, propõe-se uma metodologia capaz de calcular, para a economia brasileira, a taxa de câmbio implícita das exportações por setor CNAE a dois dígitos. O cálculo da taxa do câmbio real implícita por setor da atividade produtiva é relevante para se conhecer os incentivos à exportação e as diferenças desses incentivos entre os diversos setores da economia. Nesse sentido, os incentivos fiscais e financeiros proporcionados pelas políticas de promoção de exportações adotadas atualmente no Brasil configuram-se em um sistema de "taxas múltiplas de câmbio" para a atividade exportadora brasileira.

A taxa de câmbio implícita incorpora, no seu cálculo, os ganhos fiscais e financeiros dos exportadores provenientes de políticas de promoção de exportações. 
Constatou-se que esses mecanismos de incentivo às exportações proporcionaram variações cambiais da ordem de até $6,5 \%$ quando se consideram as exportações agregadas e o conjunto desses mecanismos no período 2004-2008. Ademais, verificou-se, também, que os ganhos são muito heterogêneos quando se consideram os vários setores da economia e os distintos mecanismos de apoio às exportações brasileiras. Diversos setores apresentaram, no período em análise, diferenças entre o câmbio nominal e o câmbio implícito superiores a $10 \%$ em todas as modalidades estudadas.

Por fim, o cálculo da taxa de câmbio implícita, $E i^{*}$, proposto neste trabalho, é conservador, pois, provavelmente, corresponde a uma subestimativa de $E i^{*}$. Isso ocorre porque, muitas vezes, ao realizar uma operação com ACC e/ou PAE, e/ou de financiamento do BNDES, o exportador obtém um ganho de arbitragem que decorre da diferença entre a taxa de juros para capital de giro observada no mercado doméstico e a taxa dada pela Libor acrescida de um spread. Entretanto, neste trabalho, optou-se por calcular os ganhos de arbitragem do exportador a partir da média aritmética entre a taxa para capital de giro no mercado doméstico e a Selic e sua diferença com a taxa dada pela Libor acrescida de um spread. Além disso, o prazo médio usado para se calcular os ganhos de arbitragem do exportador com operações de PAE adotado neste estudo também foi extremamente conservador. O Banco Central do Brasil não possui informações precisas sobre esse prazo, mas informou que há operações de PAE com prazos de até dez anos. Desse modo, optou-se por usar, para as operações de PAE, os prazos médios para os ACCs informados pelo Banco Central, que são quase sempre inferiores a um ano e normalmente inferiores a 180 dias.

Por outro lado, a taxa de câmbio implícita que decorre das operações de financiamento do BNDES calculada neste estudo deve estar superestimada, visto que o BNDES não fornece dados sobre o total de exportações de cada setor, mas tão somente o total de liberações de recursos usados nos financiamentos. Com isso, a metodologia adotada não pondera o total liberado pelo total de exportações, e admitiu-se, para o cálculo do câmbio implícito, que o total financiado coincide com o total das exportações. Entretanto, conforme se constatou na tabela 7, a participação dos recursos do BNDES no total dos recursos que correspondem aos incentivos fiscais e financeiros vinculados à atividade de exportação no Brasil foi de, no máximo, 8,6\%, ao passo que a participação dos recursos das operações com ACC e PAE foi de, no mínimo, 71,1\% ao longo do período analisado. Isso dilui os efeitos da superestimativa da taxa de câmbio implícita relacionada às operações de financiamento do BNDES quando se considera o cálculo da variação cambial agregada. Sendo assim, devem prevalecer, no cálculo da variação cambial agregada, os efeitos da subestimação da taxa de câmbio implícita presentes nos mecanismos de $\mathrm{ACC}$ e $\mathrm{PAE}^{12}$.

(12) No caso das operações que ocorrem no âmbito do Drawback, conforme salientado, a metodologia empregada apresenta um componente de superestimativa e outro de subestimativa da taxa de câmbio implícita. 


\section{Referências bibliográficas}

BIELSCHOWSKY, R. (Org.). Cinquenta anos de pensamento na CEPAL. Rio de Janeiro: Record, 2000. v. 1.

BLUMENSCHEIN, F.; LEON, F. L. Uma análise do desempenho e da segmentação do sistema de crédito à exportação no Brasil. In: PINHEIRO, A. C. et al. O desafio das exportações. Rio de Janeiro: BNDES, 2002.

CAVALCANTI, M.; RIBEIRO, F. As exportações brasileiras no período 1977/96: desempenho e determinantes. Rio de Janeiro: IPEA, 1998. (Textos para Discussão, n. 545).

DIB, M. F. S. P. Importações brasileiras: políticas de controle e determinantes da demanda. $8^{\circ}$ Prêmio BNDES de Economia. Rio de Janeiro: BNDES, 1995.

LESSA, C. Quinze anos de política econômica. São Paulo: Ed. Brasiliense, 1983.

MINISTÉRIO DO DESENVOLVIMENTO, INDÚSTRIA E COMÉRCIO EXTERIOR. Impactos do Drawback Verde-Amarelo. Brasília, DF: MDIC Assessoria Econômica. 2008. (Nota Técnica, n. 7)

PEREIRA, T. R.; MACIENTE, A. N. Impactos dos mecanismos de financiamento (ACC e ACE) sobre a rentabilidade das exportações brasileiras. Rio de Janeiro: IPEA, abr. 2000. (Texto para Discussão, n. 722)

PINTO, A. Natureza e implicações da heterogeneidade estrutural da América Latina. In: BIELSCHOWSKY, R. (Org.). Cinquenta anos de pensamento na CEPAL. Rio de Janeiro: Record, 2000.

PREBISCH, R. O desenvolvimento econômico da América Latina e alguns de seus problemas principais. In: BIELSCHOWSKY, R. (Org.). Cinquenta anos de pensamento na CEPAL. Rio de Janeiro: Record, 2000.

RODRIGUEZ, O. O estruturalismo latino-americano. Rio de Janeiro: Civilização Brasileira, 2009.

ROSSI, P.; PRATES, D. M. Crédito à exportação. Projeto de estudos sobre as perspectivas da indústria financeira brasileira e o papel dos bancos públicos. Campinas, SP: Unicamp. IE/BNDES, 2009. Disponível em: http://www.iececon.net/ arquivos/Financiamento_Exportacao.pdf.

TAVARES, M. C. Auge e declínio do processo de substituição de importações no Brasil. In: . Da substituição de importações ao capitalismo financeiro. 8 ed. Rio de Janeiro: Zahar, 1979.

VEIGA, P. M.; IGLESIAS, R. A política de financiamento à exportação no Brasil. REDIPEA/BID, 2000. 